\title{
DUKUNGAN KELUARGA TERHADAP DEPRESI PADA PASIEN LANSIA PASCA STROKE HEMORAGIK
}

\section{FAMILY SUPPORT ON DEPRESSION IN ELDERLY PATIENTS POST HEMORORAGIC STROKE}

\author{
Apri Budianto ${ }^{1}$, Rita Sari ${ }^{2}$, Rendi Setya Pratama ${ }^{3}$ \\ ${ }^{1,2,3}$ Fakultas Kesehatan Universitas Muhammadiyah Pringsewu Lampung \\ Email Correspondence: apribudianto@ umpri.ac.id
}

\begin{abstract}
Abstrack: Family Support On Depression In Elderly Patients Post Hemororagic Stroke. Stroke is a non-communicable disease that causes high morbidity and disability, thus the sufferer is prone to depression. The purpose of this study is to find the relationship betweenfamily support with the incidence of depression in the patient post stroke. Researchers found that older people who had a stroke also experienced depression to varying degrees. This research is a quantitative analytic study with a cross sectional approach. The population in this study were after stroke sufferers with an age range of > 55 years in the Work Area of the Wates Inpatient Health Center, where the sample was collected by the total sampling method so that the total sample was the total number of respondents in the population of 50 respondents, which was then tested by the technique of spearman rank.statistical tests were carried out and the researchers found results between the two variables with a p-value (0.034) which means $<5 \%(0.05)$.there is a significant relationship between family support with the incidence of depression at patient after stroke in the Wates Health Center Lampung in 2021. Patient post stroke sufferers are prone to depression caused by the lack of family support, where families who do good support will strengthen the Ability patient post stroke so that depression can be minimized.

Keywords: family support, depression, poststroke
\end{abstract}

\begin{abstract}
Abstrak: Dukungan Keluarga Terhadap Depresi Pada Pasien Lansia Pasca Stroke Hemoragik. Stroke adalah salah satu penyakit tidak menular yang menyebabkan angka kesakitan dan kecacatan yang tinggi, dengan demikian penderita rentan terhadap depresi. Tujuan penelitian ini adalah mengetahui hubungan antara dukungan Keluarga dengan kejadian depresi pada usia lanjut pasca stroke hemoragik. Peneliti menemukan bahwa penderita yang mengalami stroke juga mengalami depresi dengan tingkatan yang berbeda. Penelitian ini berjenis penelitian kuantitatif analitik dengan pendekatan cross sectional. Populasi dalam penelitian ini adalah penderita stroke hemoragik dengan rentang usia > 55 tahun di Wilayah Kerja Puskesmas Rawat Inap Wates, dimana sampel dikumpulkan dengan metode total sampling sehingga jumlah sampel adalah keseluruhan dari jumlah responden di dalam populasi yang berjumlah 50 responden, yang kemudian diuji dengan teknik rank spearman. uji statistic dilakukan dan peneliti menemukan hasil antara kedua variabel dengan $p$-value $(0,034)$ yang berarti $<5 \%(0,05)$. Terdapat hubungsn antara hubungan yang signifikan antara dukungan keluarga dengan kejadian depresi pada penderita pasca stroke hemoragik di wilayah Kerja Puskesmas Wates Lampung 2021. Penderita stroke rentan terjadi depresi diakibatkan oleh minimnya dukungan keluarga, dimana keluarga yang melakukukan dukungan yang baik akan memperkuat kemampuan penderita post stroke untuk menjalani kegiatan sehari hari sehingga depresi dapat diminimalisir.

Kata kunci: dukungan keluarga, depresi, pascastroke.
\end{abstract}

\section{PENDAHULUAN}

Penyakit tidak menular (PTM) adalah penyakit yang dianggap tidak dapat ditularkan atau disebarkan dari penderita ke orang lain. (irwan 2016). Salah satu penyakit tidak menular yaitu stroke, dimana kejadian stroke menurut Riskesdas dari tahun 2007 sampai dengan 2018 mengalami 
Vol 11 No 1 Januari 2022 | Page 176-182

peningkatan (Kemenkes, 2018).Angka kejadian stroke hemoragik di dunia tercatat sebanyak 4.120.318 kasus sepanjang 2019 dimana diproyeksikan terus mengalami peningkatan (Lindsay et al., 2019). Sementara benua Asia pada tahun 2010 menjadi peringkat keempat dengan prevalensi 4,5 juta kejadian stroke dengan usia di atas 15 tahun (Azwarli, Astuti, \& Erwinsyah, 2017).

Stroke sendiri menjadi kontributor terbesar dalam pencetus depresi, dibuktikan dengan dimana penyebab tertinggi yaitu penyakit kardiovaskular yaitu sebanyak 36,4\%. Penyakit kardiovaskuler dapat menjadi kontributor timbulnya depresi akibat dari timbulnya kesakitan dan kecacatan (Kemenkes, 2019).Tingkat depresi pasca stroke dapat disebabkan beberapa faktor yaitu beberapa diantaranya seperti lesi bagian otak, jenis kelamin, riwayat depresi, dan kondisi kehidupan sosial dalam keluarga. Keluarga yang memberi dukungan baik secara moril maupun materi berpengaruh pada tingkaat depresi penderita stroke (VIka, Syarifah, \& Rahmawati, 2017).

\section{METODE}

Penelitian yang peneliti lakukan yaitu dengan menggunakan kuantitatif analitik dengan pendekatan crosss sectional, Variabel independen dalam penelitian ini adalah dukungan keluarga dan dan variabel dependen adalah depresi lansia pascastroke. Populasi dalam penelitian ini adalah penderita yang mengalami pasca stroke di wilayah kerja Puskesmas Rawat Inap Wates yang berjumlah 50 responden. sampel dalam penelitian adalah pasien yang mengalami depresi pascastroke yang berjumlah 50 responden dimana diambil dengan teknik total sampling.

Instrument penelitian ini menggunakan lembar kuesioner dukungan keluarga dan BDI (beck depression inventory). Uji statistic dilakukan dengan metode spearman rho. Sebelum dilakukan pengambilan data, masing-masing calon responden diminta persetujuan menjadi responden dengan menandatangani lembar persetujuan dan informed consent.

\section{HASIL}

\section{Karakteristik Responden}

Tabel 4.1 Distribusi Frekuensi Karakteristik Responden Berdasarkan Usia, Jenis Kelamin Dan Pendidikan Di Wilayah Kerja Puskesmas Rawat Inap Wates Tahun 2021

\begin{tabular}{lcc}
\hline Karakteristik & $\begin{array}{c}\text { Frekuensi } \\
(\mathbf{n})\end{array}$ & $\begin{array}{c}\text { Persentase } \\
(\mathbf{\%})\end{array}$ \\
\hline Usia & & \\
- 48-51 tahun & 15 & 30.0 \\
$-\quad 52-55$ tahun & 25 & 50.0 \\
- 56-59 tahun & 10 & 20.0 \\
\hline Jenis Kelamin & & \\
- Laki-Laki & 24 & 48.0 \\
- Perempuan & 26 & 52.0 \\
\hline Pendidikan & & \\
- SD & 20 & 40.0 \\
- SMP & 14 & 28.0 \\
- SMA & 10 & 20.0 \\
- S1 & 6 & 12.0 \\
\hline Jumlah & 50 & 100 \\
\hline
\end{tabular}


Vol 11 No 1 Januari 2022 | Page 176-182

Diketahui bahwa karakteristik responden penderita stress pasca stroke sebagian besar berusia 52 - 55 tahun yaitu sebanyak 25 (50\%) responden, kemudian berdasarkan jenis kelamin sebagian besar adalah perempuan yaitu sebanyak $26(52,0 \%)$ dan berdasarkan pendidikan responden didominasi dengan tingkat pendidikan SD yaitu sebanyak 20 (40\%).

\section{Dukungan Keluarga}

Tabel 4.2 Distribusi frekuensi berdasarkan dukungan keluarga penderita depresi pasca stroke di wilayah kerja Puskesmas Rawat Inap Wates Tahun 2021

\begin{tabular}{lcc}
\hline Dukungan Keluarga & Frekuensi & Persentase (\%) \\
\hline Baik & 9 & 18.0 \\
Kurang & 41 & 82.0 \\
\hline Total & 50 & 100.0 \\
\hline
\end{tabular}

Berdasarkan tabel 4.2 didapatkan bahwa sebagian besar mendapat dukungan keluarga kurang yaitu sejumlah 41 responden, kemudian responden yang mendapat dukungan keluarga baik sebanyak 9 responden $(18,0 \%)$.

\section{Depresi Pasca Stroke}

Tabel 4.3 Distribusi frekuensi berdasarkan depresi Pasca Stroke di wilayah kerja Puskesmas Rawat Inap Wates Tahun 2021

\begin{tabular}{lcc}
\hline Depresi Pasca Stroke & Frekuensi & Persentase (\%) \\
& & \\
\hline Rendah & 18 & 36.0 \\
Sedang & 31 & 62.0 \\
Ekstrem & 1 & 2.0 \\
\hline Total & 50 & 100.0 \\
\hline
\end{tabular}

Berdasarkan tabel 4.3 didapatkan hasil bahwa responden sebagian besar mengalami depresi sedang yaitu sebanyak $31(62,0 \%)$, kemudian terdapat 18 (36,0\%) mengalami depresi rendah, dan hanya terdapat satu responden yang mengalami depresi ektreme. 
Vol 11 No 1 Januari 2022 | Page 176-182

Hubungan Dukungan Keluarga Dengan Kejadian Depresi Pada Pasien Pasca Stroke Hemoragik Tabel 4.4. Distribusi Frekuensi Hubungan Dukungan Keluarga Dengan Kejadian Depresi Pada Usia Lanjut Pasca Stroke Hemoragik Di Wilayah Kerja Puskesmas Rawat Inap Wates Tahun 2021

\begin{tabular}{|c|c|c|c|c|c|c|c|c|c|}
\hline \multirow{3}{*}{$\begin{array}{l}\text { Dukungan } \\
\text { Keluarga }\end{array}$} & \multicolumn{6}{|c|}{ Depresi Pasca Stroke } & \multicolumn{2}{|c|}{ Total } & \multirow{3}{*}{$\begin{array}{l}\mathbf{P} \\
\text { Value }\end{array}$} \\
\hline & \multicolumn{2}{|c|}{ Rendah } & \multicolumn{2}{|c|}{ Sedang } & \multicolumn{2}{|c|}{ Ekreme } & \multirow{2}{*}{$\mathbf{N}$} & \multirow{2}{*}{$\%$} & \\
\hline & $\mathbf{N}$ & $\%$ & $\mathbf{N}$ & $\%$ & $\mathbf{N}$ & $\%$ & & & \\
\hline Baik & 6 & 12,0 & 3 & 6,0 & 0 & 0,0 & 9 & 18,0 & \multirow{2}{*}{0,034} \\
\hline Kurang & 12 & 24,0 & 28 & 56,0 & 1 & 2,0 & 41 & 82,0 & \\
\hline Jumlah & 18 & 36,0 & 31 & 62,0 & 1 & 2,0 & 50 & 100 & \\
\hline
\end{tabular}

Berdasarkan tabel 4.6 didapatkan hasil bahwa responden mendapatkan dukungan keluarga kurang mengalami depresi sedang menjadi terbanyak yaitu sejumlah sebanyak 28 (56,0\%). Berdasarkan uji Rank Spearman didapatkan hasil bahwa terjadi hubungan yang signifikan antara dukungan keluarga dengan kejadian depresi pada usia lanjut pasca stroke hemoragik Di Wilayah Kerja Puskesmas Rawat Inap Wates Tahun 2021 dengan $p$-value $(0,034)$ yang berarti $<5 \%(0,05)$ dan menunjukan bahwa Ho berhasil ditolak.

\section{PEMBAHASAN}

Gambaran dukungan keluarga penderita stroke di wilayah kerja Puskesmas Rawat Inap Wates Tahun 2021

Dukungan keluarga adalah suatu system support yang diberikan keluarga kepada anggota keluarga yang mengalami gangguan kesehatan dimana di dalamnya terdapat dukungan emosional, informasional, unstrumental dan penghargaan, dengan harapan keluarga yang sakit dapat pulih ataupun meminimalisir dampak lain dari gangguan kesehatan yang dialami (Radiani, 2018).

Penderita yang mengalami pasca stroke jika mendapat dukungan keluarga yang baik akan minim menderita depresi dikarekanan kehadiran lingkungan psikosoial keluarga yang baik. Berbanding terbalik pada lansia yang mendapatkan dukungan keluarga kurang baik akan beresiko menderita depresi pasca stroke (Herawati \& Deharnitas, 2019).

Dari tabel 4.2 didapatkan bahwa sebagian besar mendapat dukungan keluarga kurang yaitu sejumlah 41 responden, kemudian responden yang mendapat dukungan keluarga baik sebanyak 9 responden $(18,0 \%)$.

Hasil penelitian ini sejalan dengan penelitian yang dilakukan Dewi dan Darliana (2017) tentang dukungan keluarga dengan depressi pada pasien pasca stroke. Hasil penelitian ini menunjukan bahwa terdapat hubungan antara dukungan keluarga dengan depresi penderita stroke dengan $p$-value $(0,000)$ $(<0,05)$.

Gambaran depresi pasca stroke di wilayah kerja Puskesmas Rawat Inap Wates Tahun 2021

Depresi merupakan gangguan psikologis berupa keabnormalan mod yang umum menyerang usia remaja sampai lansia dapat diakibatkan oleh stressor berupa tekanan kerja, proses penyakit kronis, dan sosialkultural, dan biologis (Lubis, 2016).

https://ejournal.umpri.ac.id/index.php/JIK 179 
Berdasarkan tabel 4.3 didapatkan hasil bahwa responden sebagian besar mengalami depresi sedang yaitu sebanyak $31(62,0 \%)$, kemudian terdapat $18(36,0 \%)$ mengalami depresi rendah, dan hanya terdapat satu responden yang mengalami depresi ektreme.

Penelitian yang dilakukan Kurniawati (2017) yang berjudul hubungan antara dukungan keluarga dengan tingkat depresi pada pasien pasca stroke di Rumah Sakit Umum Daerah dr. Moewardi Surakarta menemukan bahwa terdapat responden yang tidak mengalami depresi 18 (52,9\%), kemudian depresi ringan $13(38,2 \%)$ dan yang mengalami depresi sedang sebanyak $3(8,8 \%)$ responden.

\section{Hubungan dukungan keluarga dengan kejadian depresi pada penderita pasca stroke hemoragik}

Berdasarkan uji Rank Spearman didapatkan hasil bahwa terjadi hubungan yang signifikan antara dukungan keluarga dengan kejadian depresi pada penderita pasca stroke hemoragik Di Wilayah Kerja Puskesmas Rawat Inap Wates Tahun 2021 dengan $p$-value $(0,034)$ yang berarti $<5 \%(0,05)$ dan menunjukan bahwa Ho berhasil ditolak.

Menurut penelitian yang dilakukan Aryani, Amila dan Hawalia (2019) yang berjudul hubungan dukungan keluarga dengan kejadian depresi pada pasien paska stroke di Puskesmas Simpang Tiga Redelong Bener Meriah menemukan hasil bahwa hasil uji statistic chi square diperoleh hasil 0,001 yang berarti ada hubungan signifikan antara dukungan keluarga dengan depresi pasca stroke.

Faktor-faktor yang mempengaruhi tingkat depresi pasien pascastroke diantaranya seperti, kemampuan motoric. Fungsi kognitif dan dukungan keluarga. dukungan keluarga menjadi sangat penting bagi pasien pasca stroke, dimana keluarga menjadi fasilitator dan pemenuh kebutuhan pasien yang dalam proses menjalani adaptasi untuk melakukan aktivitas sehari-hari.(Reni, Suryani, \& Sasmita, 2020).

Pasien pascastroke yang dengan dukungan keluarga baik yang mengalami depresi ringan dikarenakan mendapat dukungan penuh dari keluarga yang berupa dukungan emosional, informasi, pengobatan dan bantuan aktivitas sehari-hari. Pasien pascastroke dengan dukungan keluarga baik namun mengalami depresi sedang diakibatkan oleh ketidakmampuan pasien dalam menghadapi proses penerimaan keadaan yang berbeda dari sebelum dan setelah seragan stroke (Harahap, 2015).

Pasien pascastroke mengalami depresi sedang cenderung mendapatkan dukungan keluarga yang kurang, dimana pasien minim mendapatkan bantuan dalam melakukan aktivitas sehari-hari, dukungan pengobatan, dan informasi. Berbeda dengan pasien yang mengalami tingkan depresi ringan walaupun mendapat dukungan keluarga yang minim lebih disebabkan oleh sikap penerimaan atau koping positif pasien tersebut. Pasien yang mengalami depresi berat diakibatkan oleh dukungan keluarga yang minim dan diperberat oleh koping individu yang kurang baik dan dalam jangka waktu yang lama (Karuniawati, 2017).

Peneliti berpendapat dukungan keluarga sangat penting bagi lansia pasca stroke, dimana penderita yang baru saja mengalami stroke perlu dukungan keluarga, baik berupa materi, pengobatan, bantuan aktivitas, dan moril dengan harapan, klien tersebut dapat melalui fase adaptif dengan baik sehingga resiko depresi dapat diminimalisir.

\section{SIMPULAN}

Karakteristik responden berdasarkan usia terbanyak pada rentang 52-55 tahun yaitu berjumlah 25 (50.0\%), sebagian besar berjenis kelamin perempuan sebanyk 26 (52.0\%) dan didominasi pada tingkat pendidikan SD sebanyak 20 (4,0\%) Sebagian besar responden dukungan keluarga kurang 41 (82.0\%) 31 . Hasil penelitian sebagian besar responden menderita depresi sedang $31(62,0 \%)$.Hasil analisi data 
Vol 11 No 1 Januari 2022 | Page 176-182

menunjukan bahwa dukungan keluarga berhubungan dengan kejadian depresi pada penderita pasca stroke Di Wilayah Kerja Puskesmas Rawat Inap Wates Tahun 2021 dengan $p$-value $(0,034)$.

\section{SARAN}

Penelitian ini dapat di simpulkan bahwa penderita stroke rentang sering mengalami depresi sehingga program rehabilitasi pasien paska stroke diharapkan tidak bersubjek pada penderita namun juga menyasar keluarga sebagai pemberi dukungan. Hasil penelitian ini dapat digunakan sebagai penambah pengetahuan keluarga ataupun penderita dalam mencegah depresi pascastroke, sumber pengetahuan untuk meningkatkan koping penderita pasca stroke sehingga kejadian depresi dapat diminimalkan.

\section{DAFTAR PUSTAKA}

AHA, A. H. A. (2017). Heart Disease And Stroke-2017. American Heart Association update

Amir, N. (2016). Depresi Aspek Neurobiologi Diagnosis dan Tatalaksana: Badan Penerbit Fakultas KEdokteran Universitas Indonesia.

Azwarli, Astuti, \& Erwinsyah. (2017). faktor resiko stroke di kota jambi tahun 2016. riset informasi kesehatan, volume 6.

Balitbangkes. (2018). Laporan Provinsi Lampung Riskesdas 2018. Jakarta: Badan Penelitian dan Pengembangan Kesehatan

Cahyawaty, M. I. (2017). HUBUNGAN DUKUNGAN KELUARGA DENGAN PERILAKU LANSIA DALAM MENGENTADILAK HIPERTENSI DI WILAYAH PUSKESMAS PILANGKENCENG KABUPATEN MADIUN. STIKES BHAKTI HUSADA MULIA, MADIUN.

Clavijo, L. C. (2015). Clinics Review Articles Cardiology Clinics Vaskular Desease (Vol. volume 33): University of Southern California.

Dharma, K. K. (2011). Metodologi Penelitian Keperawatan. Jakarta: CV. Trans Info Medika.

Dharma, K. K. (2013). Metode Penelitian Keperawatan. Jakarta: Trans Info Media.

Friedman, M. M. (2013). Keperawatan Keluarga: Teori dan Praktik. Jakarta: EGC.

Futriani, \& Pasaribu. (2019). faktor-faktor yang berhubungan dengan depresi pada pasien pasca stroke. jurnal antara keperawatan, volume 2.

Herawati, \& Deharnitas. (2019). Hubungan Karakteristik dengan kejadian depresi pada lansia. jurnal keperawatan jiwa, volume 7.

Irwan. (2016). EPIDEMIOLOGI PENYAKIT TIDAK MENULAR (1 ed.). Yogyakarta: CV BUDI UTAMA.

Kartini, Murtiani, \& Ilyas, M. (2013). hubungan dukungan keluarga dengan perubahan konsep diri pasen pasca stroke di poliklinik syaraf Rumah Sakit Khusus Daerah Provinsi Sulawesi Selatan. volume 3.

Karuniawati, D. (2017). HUBUNGAN ANTARA DUKUNGAN KELUARGA DENGAN TINGKAT DEPRESI PADA PASIE PASCA STROKE DI RUMAH SAKIT UMUM DAERAH Dr. MOEWARDI SURAKARTA. Universitas Muhammadiyah Surakarta, Surakarta.

Kemenkes. (2018). Riset Kesehatan Dasar. Jakarta: Kementerian Kesehatan RI.

Kemenkes. (2019). Situasi Kesehatan Jiwa Di Indonesia.

Lindsay, M. P., Norvving, B., Sacco, R. L., M.Brainin, Hacke, W., Martin, S., . . V.Feigin. (2019). Global Stroke Fact Sheet 2019: World Stroke Organization.

Lubis, N. L. (2016). Depresi Tinjauan Psikologis. Jakarta: Kencana.

Mansjoer, Suprohaita, Wardhani, \& Setiowulan. (2010). Kapita Selekta Kedokteran. Jakarta : Media Aesculapius.

Notoatmodjo, S. (2012). Metodologi Penelitian Kesehatan. Jakarta: Rineka Cipta.

https://ejournal.umpri.ac.id/index.php/JIK $1 \mathbf{1 8 1}$ 
Vol 11 No 1 Januari 2022 | Page 176-182

Nursalam. (2013). Metodologi Penelitian Ilmu Keperawatan. Jakarta: Salemba Medika.

Patu, Y. M., Wuysang, A. D., \& Maricar, N. (2018). hubungn lesi hemister serebral dan derajat klinis kecemasan pada penderita stroke iskemik. Neuroma, Volume 36.

Price, S. A., \& Wilson, L. M. (2012). Patofisiologi : konsep klinis proses-proses penyakit. Jakarta: EGC.

Siaga, A. A. (2019). Hubungan Mekanisme Koping Dengan Tingkat Depresi Pada Pasien Gagal Ginjal Kronis Yang Menjalani Terapi Hemodialisa Di Rumah Sakit Umum Derah

Dr. H. Abdul Moeloek Provinsi Lampung. Sekolah Tinggi Ilmu Kesehatan (Stikes) Muhammadiyah Pringsewu Lampung

Siregar. (2013). Metode Penelitian Kuantitatif. Jakarta: Prenada Media Group.

VIka, W. N., Syarifah, A. S., \& Rahmawati, M. (2017). hubungan status fungsional dengan tingkat depresi pada pasien stroke di ruang Flamboyan RSUD Jombang.

Wati, D. F., \& Yanti, Y. (2018). Gambaran Dukungan Keluarga terhadap Perubahan Konsep Diri Pasien Pasca Stroke di Poli Neurologi Hanafiah Batusangkar. Real in Nursing Journal, volume 1.

Wibowo, J. A. (2016). faktor faktor yang berhubungan dengan kejadian depresi pada pasien pasca stroke. Universitas Muhammadiyah Semarang, Semarang.

Wurtiningsih. (2012). dukungan keluarga pasien stroke di ruang syaraf RSUP. Dr. Kariadi Semarang. med hosp, volume 1 .

Yuliani, S. (2019). Hubungan Dukungan Keluarga Dengan Tingkat Kemandirian Activity Daily Living (Adl) Pasien Pasca Stroke Poli Syaraf Rumah Sakit Umum Daerah Dr. H. Abdoel Moeloek. SEKOLAH TINGGI ILMU KESEHATAN (STIKes) MUHAMMADIYAH

Harahap, S. (2015). Hubungan Kemampuan Fungsi Tubuh dan Dukungan Keluarga Dengan Depresi Pada Pasien Pasca Stroke. (Magister Ilmu Keperawatan), Universitas Sumatera Utara.

Karuniawati, D. (2017). Hubungan antara dukungan keluarga dengan tingkat depresi pada pasien pasca strokedi rumah sakit umum daerah $d r$. . (Prodi Pendidikan Dokter), Universitas Muhammadiyah Surakarta.

Lubis. (2016). Depresi Tinjauan Psikologis. Jakarta: Kencana.

Radiani, Z. F. (2018). Hubungan Dukungan Keluarga Dengan Kualitas Hiduo Lansia Yang Mengalami Hipertensi di Wilayah Kerja Puskesmas Mandalle Kabupaten Pangkep. (Prodi Ilmu Keperawatan), Universitas Hasanuddin.

Reni, Suryani, \& Sasmita, H. (2020). Analisa Faktor-Faktor Yang Berhubungan Dengan Tingkat Depresi Pascastroke di Rumah Sakit Stroke Nasional (RSSN) Bukit Tinggi. Jurnal Kesehatan Mercusuar, vol 3 . 